\title{
An Assessment of the Food and Physical Activity Environment on a University Campus
}

\section{Kayla Castellitto and Nurgul Fitzerald}

Kayla Catellitto conducted this study as a part of her George H. Cook Honors Thesis research, while she was an undergraduate student at Rutgers, The State University of New Jersey, School of Environmental and Biological Sciences. Dr. Nurgul Fitzerald is an Associate Professor / Extension Specialist at the Department of Nutritional Sciences at Rutgers University.

\begin{abstract}
Large percentages of college students are reported to be overweight and sedentary and do not consume the recommended amounts of fruits and vegetables. These outcomes can be influenced by the students' environment. The purpose of this study was to determine the level of healthfulness and environmental supports on Rutgers University's Cook Campus (RU) - one of the five Rutgers campuses-by examining campus food and physical activity environment, and related policies. As a part of the nationwide Get Fruved study on over 90 college/university campuses, the Healthy Campus Environmental Audit (HCEA) instrument was used to assess dining establishments, vending machines, recreational environment, and policies at RU. RU scores were compared to the original scales and to the average of the other Get Fruved universities/colleges. RU's healthfulness scores for dining halls/cafeterias, recreational environment, vending machine supports, and stimulants policy were on the higher end of the scales and above the averages of other Get Fruved schools. However, RU's scores indicated limited healthfulness in fast-food/sit-down restaurants; walking/biking supports; availability of healthy snacks and beverages in vending machines; healthy eating policies; and policies encouraging physical activity and chronic disease prevention. This study identified the strengths and weaknesses in RU's campus environment and in RU's policies for healthy eating and active living. These results can be used to support a healthier campus environment.
\end{abstract}

Key Terms: active environment, audit, built environment, environmental assessment, food environment, health/wellness promotion, healthy eating, nutrient density, policy, university/college campus, vending machines

\section{Introduction}

Emerging adulthood ( 18 to 25 years of age) is considered an important stage for maintaining long-term health behavior patterns (Nelson, Story, Larson, Neumark-Sztainer, \& Lytle, 2008). Yet, the lifestyle changes college students experience can make establishing healthy long-term behaviors difficult and put them at risk of gaining weight. These changes may include moving 
out of the family home; changes in financial responsibilities; unhealthy food options on campus; and unhealthy food habits like late-night, alcohol-related, or stress-related eating (Nelson, Kocos, Lytle, \& Perry, 2009). Additionally, large proportions of college students experience stress. In a national survey of college students, $45 \%$ reported "more than average" level of stress, and $13 \%$ reported high levels of stress (American College Health Association, 2018). Chronic stress may be linked to weight gain (Torres \& Nowson, 2007). Gaining weight during college years can have long-term effects: being moderately overweight in early adulthood and gaining weight in adulthood have both been shown to increase risks of developing major chronic diseases such as cardiovascular diseases, diabetes, and certain cancers (de Mutsert, 2014). Therefore, it is important that college students have easy access to healthy food options and physical activities on campus.

Previous research has shown that many college students are at high risk of being overweight or obese. According to the American College Health Association ([ACHA], 2018) National College Health Assessment, which surveyed 88,178 students, large proportions of the participants were overweight (23.8\%) or obese (16.2\%). In a study of 67 first-year college students, it was reported that almost $75 \%$ of the students had gained weight during their first year in college. Over the seven-month study period, their average weight gain was 3.1 kilograms (7 pounds), and average percentage of body fat gained was 0.9\% (Hoffman, Policastro, Quick, \& Lee, 2006). The exact causes of such weight gain were uncertain, but it was speculated to be because of decreased physical activity (Butler, Black, Blue, \& Gretebeck, 2004) and lifestyle changes like decreased leisure time and increased alcohol consumption (Hoffman et al., 2006).

The ACHA assessment also revealed low levels of fruit and vegetable intake among college students. Only $4.8 \%$ reported eating the recommended levels of five or more servings of fruits and vegetables a day. College campuses can affect food and beverage intake patterns through dining halls, restaurants, convenience stores, markets, food courts, and vending machines. Because the environment plays a role in what students consume (Stokols, 1992), it is important to examine the types of foods these venues provide. An assessment of dining establishments on 15 college campuses across the United States indicated that campus restaurants offered healthier food and beverage options in comparison to off-campus restaurants; still, they offered large portion sizes and "combo" meals that encouraged overeating (Horacek et al., 2012). Campus food environment is also likely to influence students who commute to campus. A study of 1,059 off-campus students in two Minnesota colleges found that $45 \%$ of the students reported purchasing foods or beverages from at least one campus venue more than three times per week. Students who frequently purchased foods from these venues reported buying foods that were high in fat and added sugar; they also reported eating breakfast less frequently and purchasing more fast-food on campus. Students who brought their own lunch from home had healthier dietary intake patterns (Pelletier \& Laska, 2013).

Vending machines are a convenient way for students to obtain snacks throughout their school day. In an assessment of 2607 vending machines at 11 colleges, it was found that the most 
commonly available snacks were chips, pretzels, other salty snacks, and sweet treats like candy (Byrd-Bredbenner et al., 2012). Most of these snacks were low in fiber and high in calories and fat; about half of the snacks were high in sugar. A majority of the available beverages were high in calories and sugar (Byrd-Bredbenner et al., 2012). These studies suggest that food and beverages available in vending machines limit healthy choices and promote low nutrient, energy-dense snacks as the easy choice.

Physical activity, a key component of preventing unwanted weight gain, can be impacted by the availability of recreation programs and facilities on campus. The ACHA (2018) assessment reported low levels of physical activity among college students. More than half (53\%) of the students did not meet the physical activity recommendations of moderate-intensity (at least 30 minutes on five or more days/week) or vigorous-intensity exercises (at least 20 minutes on three or more days/week). In a study completed at 13 colleges/universities, researchers concluded that while the programs, classes, and equipment available at the recreation facilities supported healthy lifestyles, the facilities' policies (equipment accessibility, safety features, weather accommodations, transportation, and fees) and the built environment (bike rack availability and accessibility, presence of health promotion signs, and accessibility and cleanliness of stairwells) did not support healthy lifestyles (Horacek et al., 2014). There were very few recreational screening policies for at-risk students and promotional signs for daily activities like taking the stairs. Exercise classes were not offered on weekends when students had most of their spare time. Exercise spaces were rated insufficient for use during peak hours, and secondary facilities (smaller versions of primary recreation facilities) lacked the quality of primary facilities. Researchers also reported good walkability but low bikeability across the campuses.

In summary, the literature indicates that college is a period marked by changes, which can put students at risk of becoming overweight or obese. College campus environments can influence students' eating and physical activity patterns through eating establishments, vending machines, recreation centers, and policies related to these facilities. The objective of this study was to comprehensively evaluate the healthfulness of the food and physical activity environment on a university campus through environmental and policy assessments. These assessments could serve as a basis for identifying policy and environmental changes that promote health on campus.

\section{Methodology}

\section{Study Location and Setting}

This study was conducted at the Cook Campus of Rutgers, The State University of New Jersey in New Brunswick, NJ during the 2017-2018 school year. It was a part of the Get Fruved study, which included more than 90 universities and colleges across the United States. The original Get Fruved study was funded by United States Department of Agriculture (award number 2014- 
67001-2185) and administered by University of Tennessee (UT) to promote healthier lifestyles on college campuses (Get Fruved, 2017). The current study location was limited to only one (Cook Campus) of Rutgers' five campuses.

For the environmental audits, the campus area was defined as the space within a 1.5 mile radius of the Cook Campus Center. This was chosen to be the center of the campus because it is a place where many students gather, and it is located near student life facilities (multiple residence halls, dining hall, recreation center, laundry and postal services, and bus stops). The website "Draw Radius Circles on a Map" was used to draw the radius from the campus center using Google maps (Draw Radius Circles on a Map, 2017).

\section{Assessment Methods}

The Healthy Campus Environmental Audit (HCEA) was used to help determine aspects of the campus environment that might affect students' health behaviors. The HCEA is composed of five audits focusing on campus environmental demographics (CA), dining environment (FRESH audit), recreation facilities (PACES audit), policies (POINTS audit), and vending machines (VENDing audit) (See Supplemental Materials for details). These audits have been validated in studies completed on various campus environments (Horacek et al., 2019a, 2019b, 2019c). The audits were conducted by teams of two student researchers. The student researchers underwent audit-specific online training prior to collecting data. This training included reading the audit-specific protocol, completing the training videos, and passing quizzes with an $80 \%$ or higher score. Collected data were directly entered into UT's online survey portal, de-identified by the Get Fruved administrative team at UT, and sent back to Rutgers for use. The study was approved by the Institutional Review Boards of UT and Rutgers.

\section{Statistical Analyses}

The environmental audit data were received from UT in a de-identified format. Results from each audit included Rutgers' scores as well as descriptive statistics-minimum, maximum, mean scores and standard deviations-from the national sample (that is, all of the participating Get Fruved schools that completed the same audits). For the interpretation of Rutgers' data, the results were compared to both the maximum possible audit scores and the national average data. The HCEA scores do not currently include specific cutoff points like low versus high or failure versus success. Therefore, the interpretations of the scores are based on the comparisons to the national average and the maximum possible score within each scale.

\section{Results}

\section{Campus Environmental Demographic Audit}

More than half of the campus population $(n=3,428)$ in this study were female $(62.1 \% ; 37.9 \%$ male). Slightly more than a half of them were reported to be White (51.1\%), $14.1 \%$ were 
Hispanic, $7.0 \%$ were Black, and $27.8 \%$ were listed as Other. A small proportion (10.2\%) of the students were out-of-state residents. In terms of food access in the city of New Brunswick, there were $0.1-0.2$ grocery stores per 1,000 population and $0.8-1.0$ restaurants per 1,000 population.

\section{FRESH audit}

Food score, measured on a scale of 60 , indicates the variety of the available foods. Rutgers received a food score of 20.8 (34\%) for restaurants and 45.3 (76\%) for dining halls/cafeterias (Figure 1). Restaurants received lower scores because they had more energy-dense food options, less whole grains, and fewer lean meat options. Dining halls, meanwhile, had healthier options such as a salad bar, low-fat desserts, healthier beverages, and lower-fat entrées/sides. Rutgers' food score for restaurants was similar to the national average (20.3), but the food score for dining halls/cafeterias was higher than the national mean score of 35.9.

Support score, measured on a scale of 40 , includes the environmental supports to make healthy food choices. Rutgers received a support score of 19.1 (48\%) for restaurants and 25.3 (63\%) for dining halls/cafeterias. Restaurants scored lower because their healthy supports were limited; they charged extra for healthy substitutions, charged higher prices for healthier foods, and did not offer nutrition information at some locations. Additionally, some restaurants were found to have practices encouraging overeating. These included larger portion sizes for entrees and beverages; and signs, deals, or promotions for less healthy options. Similarly, audited dining halls included all-you-can-eat buffets, which encourages overeating. However, dining halls also offered supportive strategies for healthy eating. They priced healthier and less healthy options similarly. Further, the dining halls implemented trayless dining service, where students take their food using one plate at a time rather than fitting multiple items on a tray. This service is designed to promote sustainability and discourage overeating. In addition, dining halls offered smaller cup sizes for beverages, which can help discourage overconsumption. Rutgers' support scores for restaurants were similar to the national mean, while Rutgers' support scores for dining halls/cafeterias were slightly higher than the national average. 
Figure 1. FRESH audit results at Rutgers Cook Campus and national sample of universities ${ }^{1}$ in the Get Fruved study

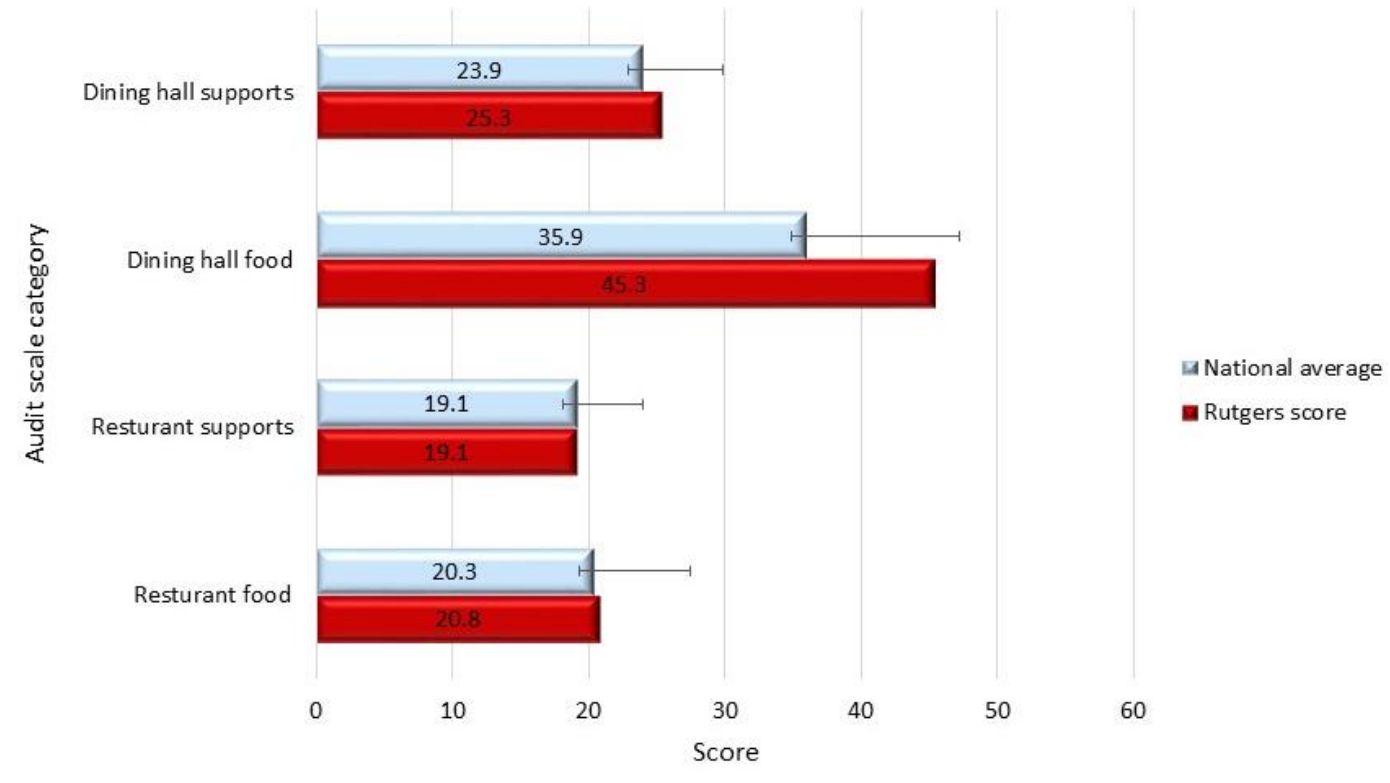

${ }^{1}$ FRESH audit evaluated the availability of types and preparation descriptions of foods, and supportive strategies for making healthy dining decisions. Food scale score range: $0-60$; support scale range: $0-40$. National sample $(n=60)$ included 384 restaurants and 117 dining halls.

\section{PACES audit}

The facility support score indicates a facility's accessibility and the quality of its staff. Rutgers' score was 9.0 (60\%), which was higher than the national sample's average score of 6.4 (Figure 2 ). Recreation facility staff's availability and competence contributed to the higher scores. The equipment score, measuring the quality of exercise equipment itself, was 16.0 (80\%) for Rutgers, compared to the national sample average of 12.4. Availability of a wide variety of equipment, including aerobic and strength training equipment, contributed to this higher score. For its walk/bike score-a measure of facility support for walking and biking-Rutgers received an 8.0 (53\%), whereas the national average was 7.0. The audit detected that Rutgers recreation facility only had one bike rack available for use, which had about $41-60 \%$ of its spots open. The facility total score, a sum of all the subscores, was 33.0 (66\%) for Rutgers and 25.8 for the national sample. The campus score, which included the quality and extensiveness of health and fitness programs, was 46 (66\%) for Rutgers in comparison to the national sample's mean of 45.0. Among the contributing factors for higher Rutgers campus score were the wide variety of indoor and outdoor amenities (e.g. pool, basketball courts, roller hockey rink, racquetball court), several intramural sports, health/wellness activities and fitness classes. 
Figure 2. PACES audit results at Rutgers Cook Campus and national sample of universities ${ }^{1}$ in the Get Fruved study

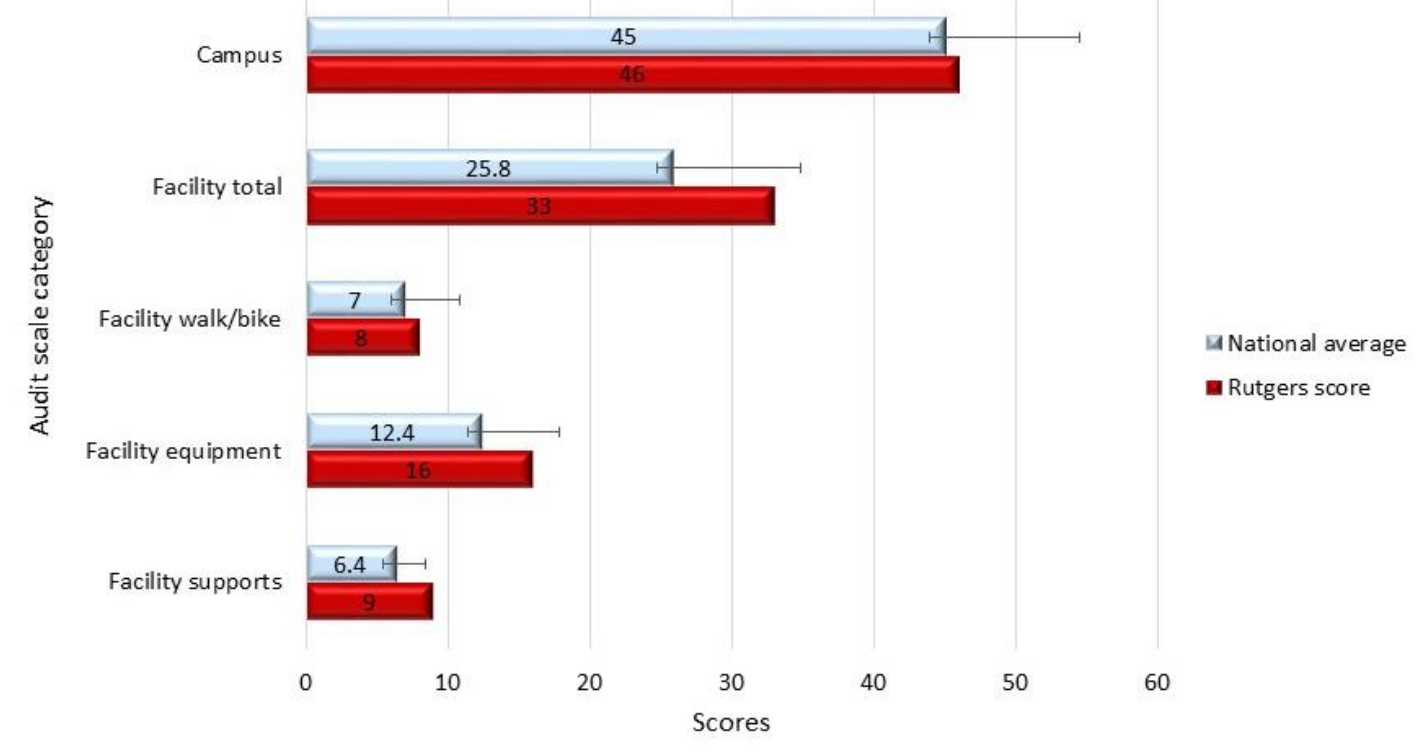

${ }^{1}$ PACES audit evaluated individual recreation facilities and programs as well as the overall campus recreation environment. Facility supports scale range: $0-15$; facility equipment scale range: $0-20$; walk/bike scale range: $0-15$; facility total scale range: $0-50$; campus scale range: $0-70$. National sample $n=58$.

\section{POINTS audit}

Rutgers received a score of $100 \%$ for support to limit drugs and alcohol (stimulants), compared to the national sample mean of $84 \%$ (Figure 3 ). Rutgers received a $0 \%$ for both chronic disease prevention support and active environment support, while the national sample averages were $7.0 \%$ and $14.9 \%$, respectively. The audit did not detect any chronic disease prevention and active environment policies, such as chronic disease online education or physical activity during work hours. Rutgers' score for supporting healthy eating was 34\%, higher than the national sample score. The overall score for student support (in relation to employees) was also $34 \%$, ranking Rutgers slightly above the national sample. This audit also evaluated other policies that were not detected at the audit sites, such as minimum and maximum nutrition standards, healthy food labeling programs, and food taxes/subsidies. Rutgers' score for the comprehensiveness of policy-that is, how well policies are monitored and enforced-was $21 \%$ in comparison to $19 \%$ for the national sample. This suggests some, but not all, policies were enforced. 
Figure 3. POINTS audit results at Rutgers and national sample of universities ${ }^{1}$ in the Get Fruved study

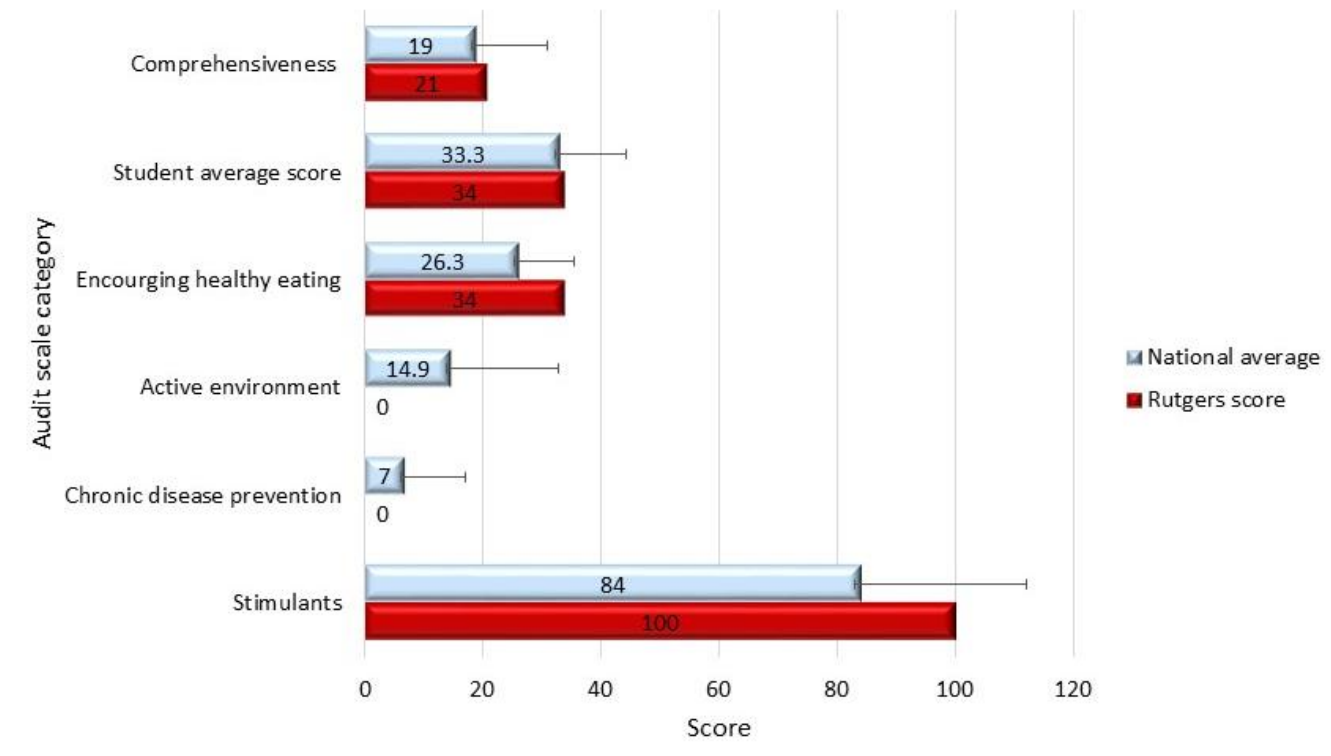

1 POINTS audit measured the extensiveness and quality of health promotion and obesity prevention interventions, programs, and policies on campus. All scales ranged from 0-100. National sample $n=52$.

\section{VENDing audit}

Of the items in the audited snack machines at Rutgers, $38 \%$ were unhealthy, $34 \%$ were somewhat healthy, and $28 \%$ were healthy (Figure 4 ). The total snack nutrient density score was 3.3 (out of 7), which was similar to the national sample mean of 3.02. Snacks that were considered unhealthy included candies, chocolates, regular chips, and cookies. Healthy snacks included baked/kettle chips, fruit snacks, granola bars, and unsalted nuts. Of the items in the audited beverage machines at Rutgers, $55 \%$ were unhealthy, $22 \%$ were somewhat healthy, and $23 \%$ were healthy. Rutgers' total beverage nutrient density score was 1.2 (out of 4 ), with the national sample mean being 1.09. Beverages such as regular sodas, iced tea, lemonade, and energy drinks were considered unhealthy. Water (flavored and unflavored) was considered healthy. 
Figure 4. VENDing audit results at Rutgers Cook Campus and national sample of universities ${ }^{1}$ in the Get Fruved study

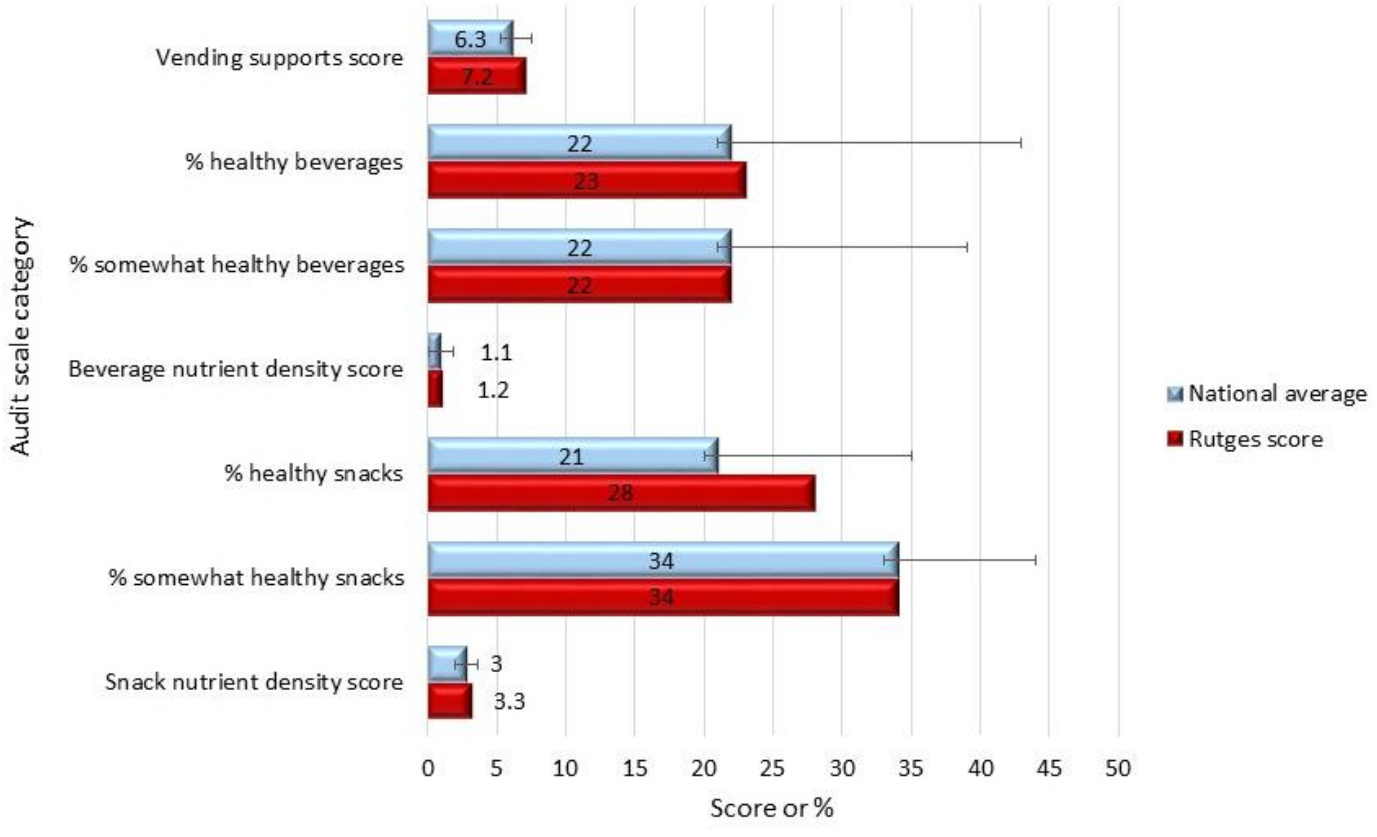

${ }^{1}$ VENDing audit assessed the availability of healthy snacks/beverages and nutrient density of the snacks in the vending machines on campus. Snack nutrient density scale range: $0-7$; Rutgers $n=16$. Beverage density scale range: $0-2$; Rutgers $n=4$. National sample $n=24$.

The VENDing supports score for Rutgers was $72 \%$, which was higher than the national sample's score. Availability of vending machines and the fact that many of the machines contained specific nutrition information for each product weighed positively on Rutgers' score. On the other hand, healthier products were often more expensive than unhealthy products, which weighed negatively on the score.

\section{Discussion}

The purpose of this study was to determine the healthfulness of the food and physical activity environment on Rutgers University's Cook Campus. Compared to the audit scales, Cook Campus scores showed limited healthfulness in some categories. These included food quality and environmental support at fast-food and sit-down restaurants; healthy snack and beverage availability in vending machines; walking and biking supports; and policy supports (with the exception of policies about stimulants). However, Rutgers scored higher than the national sample average for dining hall and cafeteria foods and supports; recreation facility and fitness programs; policies about stimulants and healthy eating; and supportive messaging in vending machines. 
The CA audit illustrated the diversity of Rutgers' Cook Campus. A diverse background among students can play a role in their food and beverage intakes, levels of physical activity, and health outcomes (U.S. Department of Agriculture \& U.S. Department of Health and Human Services, 2015). Students can have different food preferences, attitudes about their weight, and beliefs about physical activity. In addition, the campus environment is likely to influence the students' choices, social norms, and values by controlling the availability of food, beverage and physical activity options. The CA audit found that the City of New Brunswick had a high number of restaurants per capita when compared to the audit scale, and that many of these restaurants were outside the campus but within the 1.5 mile radius from the campus' student center. This study analyzed the healthfulness of 22 (close to 30\%) of these restaurants in order to determine how they may influence the overall healthfulness of the food environment for the students. Thus, it is important to look at the campus demographics and environment to examine the needs that can be addressed in future health promotion interventions.

The FRESH audit data indicated that Rutgers' dining halls and cafeterias showed a higher level of healthfulness ( $76 \%$ on the food scale and $63 \%$ on the support scale) than the fast-food and sit-down restaurants ( $34 \%$ on the food scale and $48 \%$ on support scale). The dining halls and cafeterias had significantly higher scores compared to the national sample, while the restaurants' scores were similar to the national average. Dining halls and cafeterias offered healthful food options and provided environmental supports like signage (e.g. vegan, Meatless Monday), appropriate portion sizes, and nutrition information. Still, there appears to be room for improvement in supporting healthier options. Placing consistent and attractive signage next to the healthier meal options could make it easier for students to make better food choices; this strategy has been successfully implemented by some of the other schools in the Get Fruved study. Restaurants' lower healthfulness scores were consistent with previously published research that found restaurants offered large portion sizes and combo meals, thus encouraging overeating (Horacek et al., 2012). Other Get Fruved schools marketed healthy foods and costeffective meal deals at point of selection. Additionally, they provided tastings of healthy food choices to tempt patrons to buy these products. Such strategies could improve the food environment at Rutgers as well.

The PACES audit data indicated that Rutgers' recreational facilities moderately supported healthfulness. The facilities' staff, equipment, and campus recreation programs showed $60 \%$ to $80 \%$ healthfulness and environmental support. The facility support and equipment scores were above the national averages; these results concur with previous data that showed high ratings for overall facilities and equipment available to students (Horacek et al., 2014). Rutgers' scores can be further improved by adopting strategies from other Get Fruved schools. For instance, Rutgers could increase the number and variety of fitness classes, provide free fitness assessments to encourage the use of programs and facilities, and offer "Late Night at the Gym" (open between $10 \mathrm{pm}$ and $2 \mathrm{am}$ ) as an alternative to partying. In addition, Rutgers' walk/bike features, like bike racks and stairwells, showed room for improvements: its score was 53\%, which was similar to the national sample's score. These findings are somewhat consistent with 
published research, which found very few policies to help prevent obesity and very few promotional signs for daily activities like taking the stairs (Horacek et al., 2014).

The POINTS audit indicated that Rutgers' drug and alcohol policy was excellent (100\% score) and was above the national average. However, this study did not find any policies for chronic disease prevention and active environment, and these results were below the Get Fruved schools' averages. Other Get Fruved schools with higher scores have implemented strategies such as advocating for a walkable campus and banning cars from campus. Policies for encouraging healthy eating (score of 34\%), monitoring/enforcement (21\%), and the average student policy scores (34\%) were on the lower end of the scales for Rutgers, although the healthy eating policy score was above the national average. Some of the other Get Fruved schools have set nutrition guidelines to standardize healthier dining options and have pledged to use local and community-based sources.

The VENDing audit indicated that the snack and beverage machines have limited healthful options but promising environmental supports (e.g., good product pricing, nutrition information). The mean snack and beverage nutrient density scores were only in the "somewhat healthy" category, but the environmental support score was $72 \%$. The snack and beverage nutrient density scores were generally similar to the scores from the national sample. More than half of the beverages in the audited vending machines were considered unhealthy, thus limiting students' healthy choices. This is consistent with previous research that found majority of the beverages in vending machines were sugary, calorie-dense beverages that limits students' healthy choices (Byrd-Bredbenner et al., 2012). To further improve these scores, Rutgers could post signage highlighting healthier choices. For example, one of the Get Fruved schools has been using "healthy-choice selection buttons" for snacks with less than 200 calories, less than 10 percent of calories from saturated fat, less than $60 \mathrm{mg}$ cholesterol, no trans fat, and less than $230 \mathrm{mg}$ sodium.

This study presents the results of the comprehensive campus environmental assessments that were not previously published. The study methods, developed by a collaborative team from eight universities, have been validated through testing in multiple university campuses across the country. The original collaborative team collected and managed data from the participating universities and colleges centrally, allowing for comparisons between local data and the national sample's averages. However, because national data were not collected by the Rutgers research team, the authors were unable to conduct further statistical analyses to test whether the differences between Rutgers' and other universities' scores were statistically significant. Therefore, the other universities' scores were only used as a relative benchmark to narratively compare Rutgers' scores. Another limitation of this study was its restriction to only one of Rutgers' five campuses (Cook Campus) due to time and budget constraints. Therefore, this study is not a representative sample of other Rutgers campuses or Rutgers University as a whole. In the future, including other Rutgers campuses could allow researchers to perform statistical analyses on the scores from different campuses. This would help determine the 
differences between various locations on campus. In addition, the beverage machine audits were limited to a small sample size because many of the machines had covered front panels and therefore, accurate data could not be collected from all. Lastly, the POINTS audit did not assess university policies about facilitating stress relief, even though stress may have an impact on weight gain.

In summary, Rutgers' healthfulness scores for dining halls and cafeterias, recreational environment (facilities, equipment, supports, and campus programs), and the vending machine supports were on the higher end of the environmental audit scale; the drug and alcohol policy scored particularly well. These scores were also above the averages of the national sample of Get Fruved schools. However, Rutgers scores were lower in categories like fast-food and sitdown restaurants; healthy snacks and beverages available in vending machines; walking and biking supports; and the policies to support healthy eating. This study also detected weaknesses in the policies for encouraging physical activity and preventing chronic diseases: these scores were lower compared to the national sample.

These audits comprehensively determined areas of strengths and weaknesses that can help direct further efforts toward a healthier food and physical activity environment on campus. These audit scales are not meant to classify campus environments into good versus bad or success versus failure. The audit scores provide a baseline for each school as well as a benchmark average score from a wide variety of schools across the United States. It is possible that additional benchmarks can be developed by gathering the best practices from all participating schools. These results can be good starting points for students, campus organizations, and administrators hoping to implement environmental and policy changes and seeking to explore additional strategies for supporting healthy lifestyles on campus.

\section{Acknowledgements}

This material is based upon work that was supported by the National Institute of Food and Agriculture, U.S. Department of Agriculture, under award number 2014-67001-21851 (Get Fruved Study PI: Sarah Colby, University of Tennessee). Any opinions, findings, conclusions, or recommendations expressed in this publication are those of the author(s) and do not necessarily reflect the view of the U.S. Department of Agriculture. We would like to thank the original Get Fruved study team, and especially the administrative team at the University of Tennessee and HCEA group at Syracuse University for their guidance; Haifa Matos (Rutgers Institutional Research and Academic Planning), Dave Donlon (Rutgers Dinning Services), Nathan Johnson, Brain Cousin (Campus Residence Departments), and Dr. Judith Storch (Cook Campus Deans Office) for their assistance during the environmental audits; Kappa Omicron Nu Honor Society members Radwa Nassar, Yulissa Pereira, Nada Ismail, Jamie Schroeder, Nadine Glowzenski, and Kim Manna for their assistance during the audits and reporting, and Dr. Worobey for his review of K. Castellitto's research thesis, which is the basis of this paper. Partial 
results of this research have been presented as a poster at the New Jersey Academy of Nutrition and Dietetics Annual Meeting in May 2018.

\section{References}

American College Health Association. (2018). National College Health Assessment II: Reference Group Executive Summary Spring 2018. Handover, MD. Retrieved from https://www.acha.org/documents/ncha/NCHAII_Spring_2018_Reference_Group_Executive_Summary.pdf.

Butler, S.M., Black, D.R., Blue, C.L., \& Gretebeck, R.J. (2004). Change in diet, physical activity, and body weight in female college freshman. American Journal of Health Behavior, 28, 24-32.

Byrd-Bredbenner, C., Johnson, M., Quick, V.M., Walsh, J., Greene, G.W., Hoerr, S., ... Horacek, T.M. (2012). Sweet and salty. An assessment of the snacks and beverages sold in vending machines on US post-secondary institution campuses. Appetite, 58, $1143-$ 1151.

Country Health Rankings \& Roadmaps (2017). Key Finding Report. Retrieved from http:/ / www.countyhealthrankings.org/

de Mustert, R., Sun, Q., Willett, W.C., Hu, F.B., Van Dam, R.M. (2014). Overweight in early adulthood, adult weight change, and risk of type 2 diabetes,card iovascular diseases, and certain cancers in men: a cohort study. American Journal of Epidemiology, 179 (1 1): 1353-1365.

Draw Radius Circles on Map. (2017). Retrieved from http://obeattie.github.io/gmapsradius $/$ ?lat $=51.500358 \& \operatorname{lng}=-0.125506 \& z=10 \& u=m i \& r=5$.

Get Fruved. (2017). Fruved $=$ more than fruits and vegetables. Retrieved from http://fruved.com/what-2/.

Hoffman, D.J., Policastro, P., Quick, V., \& Lee, S.K. (2006). Changes in body weight and fat mass of men and women in the first year of college: a study of the "freshman 15 ". Journal of American College Health, 55, 41-45.

Horacek, T.M., Erdman, M.B., Byrd-Bredbenner, C., Carey, G., Colby, S.M., Greene, ... White, A.B. (2012). Assessment of the dining environment on and near the campuses of fifteen post-secondary institutions. Public Health Nutrition, 16, $1186-1196$.

Horacek T.M., Simon M., Dede Yildirim E., White A.A., Shelnutt K.P., Riggsbee K.,...Brown O. (2019a). development and validation of the policies, opportunities, initiatives and notable topics (POINTS) audit for campuses and worksites. International Journal of Environmental Research and Public Health, 16, 778.

Horacek, T.M., White, A.B, Byrd-Bredbenner, C., Reznar, M.M., Olfert, M., Morrell, J.S., ...Thompson-Synder, C.A. (2014). PACES: A physical activity campus environmental supports audit on university campuses. American Journal of Health Promotion, 28, $105-$ 117. 
Horacek T.M., Yildirim E.D., Matthews Schreiber M., Byrd-Bredbenner C., Colby S., White A.A., ... Kattelmann K. (2019b). Development and validation of the vending evaluation for nutrient-density (VEND)ing audit. Int J Environ Res Public Health, 16, 514.

Horacek T.M., Yildirim E.D., Seidman D., Byrd-Bredbenner C., Colby S., White A.A., ... Kattelmann K. (2019c). Redesign, field-testing, and validation of the physical activity campus environmental supports (PACES) audit. Journal of Environmental and Public Health, 2019, 1-13.

Nelson, M.C., \& Kocos, R., Lytle, L.A., Perry, C.L. (2009). Understanding the perceived determinants of weight-related behaviors in late adolescence: a qualitative analysis among college youth. Journal of Nutritional Education and Behavior, 41, 287-292.

Nelson, M.C., Story, M., Larson, N.I., Neumark-Sztainer, D., \& Lytle, L.A. (2008). Emerging adulthood and college-aged youth: an overlooked age for weight-related behavior change. Obesity Journal, 16, 2205-2211.

Pelletier, J.E., \& Laska, M.N. (2013). Campus food and beverage purchases are associated with indicators of diet quality in college students living off campus. American Journal of Health Promotion, 28, 80-87.

Rutgers, The State University of New Jersey. (2017). Facts \& Figures. Rutgers University-New Brunswick. Retrieved from http://newbrunswick.rutgers.edu/about/facts-figures.

Stokols, D. (1992). Establishing and maintaining healthy environments toward a social ecology of health promotion. American Psychologist, 47, 6-22.

Torres, S.J., \& Nowson, C.A. (2007). Relationship between stress, eating behavior, and obesity. Nutrition, 23, 887-894.

U.S. Department of Agriculture, Economic Research Service. (2017). Go to the Atlas. Retrieved from http://www.ers.usda.gov/data-products/food-environment-atlas/go-to-theatlas.aspx

U.S. Department of Agriculture, U.S. Department of Health and Human Services. (2015). Dietary Guidelines for Americans 2010-2015. Retrieved from https:// health.gov/dietaryguidelines/2015/guidelines/chapter-3/social-ecologicalmodel/. 